\title{
Identification of Gaps and Requirements in Smart Supply Chain Management
}

\author{
Richa Loohach \\ Research Scholar (AcSIR) \\ CSIR-CEERI, Pilani, India
}

\author{
S.A. Akbar, PhD \\ Chief Scientist \\ CSIR-CEERI, Pilani, India
}

\begin{abstract}
Perishable food industry involves very high rate of wastage due to poor management of food products throughout the supply chain. Also cold chain storage is also not maintained properly which leads to spoilage of the food products. To minimize the food wastage, use of new technologies like RFID we can now manage each consignment of food items using web ontologies. Some ontologies are already developed which are able to tackle some problems of the supply chain like tracking and tracing of food products in food supply chain but other concerns like automated demand forecast and decision making, handling logistics, monitoring cold storage etc. Also need the attention while developing ontologies for perishable food supply chain.
\end{abstract}

\section{General Terms}

Cognitive, supply chain, Artificial Intelligence

\section{Keywords}

Food Supply chain, ontology, smart supply chain management, perishable food.

\section{INTRODUCTION}

The food supply chain for the perishable goods starts from farmers, then comes the manufacturers who turn the raw material into palatable products and goods, this may involve several stages of processing and several manufacturing partners. Next in the chain is the packager. Then the distributors and transporters move the food supplies by road, rail, sea or air. Once the product arrives at the destination, it goes to the Retailers and finally to the consumer this completes the supply chain for perishable food (Fig. 1). The perishables food sector industry involves above-index gross margins and waste, large variations in volumes-to-sales ratios (depending on seasonal and climatic patterns) can be seen and it is a showcase for brand equity and risk throughout the world. Now a days consumers are better informed, and are influenced by marketing campaigns that focus on their health and well-being, and their desire for fresher, more nutritious options. Fig.1, Hence it is a huge challenge for Retailers to provide the freshest products to customers, since doing so is not bound to a single business function; merchandising, store operations and the supply chain all play a collaborative role in managing and maintaining freshness and reducing wastage in the perishables cycle[1].

Wastage in the perishable fresh produce fruits and vegetables supply chain from harvesting stage till it reaches the consumer is very high in emerging markets like India. Food losses represent the wastage of natural resources which are inputs for food production. To meet the global food demand for increasing population, it is important that not only the food production be considerably increased but also it is equally imperative that the causes of food waste be rightly identified, prioritized and addressed. Both the lack of an integrated approach and poor management of the supply chain are attributed to this wastage [1]. On supply chain applied to perishable food, products deteriorate themselves over time in rates highly dependent on temperature and humidity and its situation might be similar in some aspects in comparison with applications on manufacturing [2].

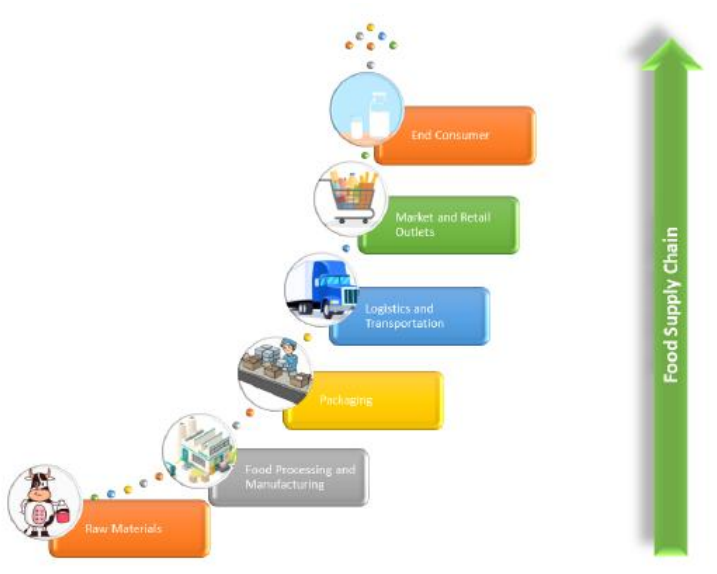

Fig. 1. Food Supply Chain

As a result, ASSOCHAM has also highlighted that India incurs post-harvest fruits and vegetable losses worth over Rs 2000 Billion each year largely owing to the absence of food processing units, modern cold storage facilities and a callous attitude towards tackling the grave issue of post-harvest losses. Associated Chambers of Commerce and Industry of India (ASSOCHAM, 2013) [3]. India has progressed from being deficient in milk production at 20 million MT in 1970 to becoming the world's largest milk producer at 160 million MT, accounting for 18.5 per cent of global milk production. Further, India is expected to emerge as the largest dairy producer by 2020 [4].

\section{LITERATURE REVIEW}

Perishable Food loss can be minimized by the efficient supply chains. The major contributors to food waste in the supply chain are processing waste, lack of cold-storage facilities, process contamination, improper packaging, transportation losses and higher inventory due to poor forecasts. When these inefficiencies in the fruits and vegetable supply chain are addressed leading to the minimum loss of food from harvesting to the point of consumption, it has enormous economic, social and environmental benefits. Managing fresh food supply chains is very complex with the recently increased concern of public health, food safety, food quality, demand and price variability, and the limited lifetime of these products [5]. Through the use of wireless technologies, routing optimization, and shared Point of Sales (POS) data, 
the DSD (direct store delivery) supplier can more quickly sense what is moving through the store [6]. Ontology on the other hand is the study of the categories of things that exist or may exist in some domain, and they provide a common vocabulary for the purpose of knowledge sharing, communication and reuse about some topic. Viewed as a conceptualization of general knowledge into understandable and readable formats, ontologies are precious tools for supply chain decision-making situations [7]. Grubic, Tonci et. al. [8] reviews several supply chain management ontologies like Enterprise ontology, TOVE ontology, IDEON ontology, Manufacturing system engineering ontology etc. and found few gaps like Apart from the EO and TOVE ontologies all other supply chain ontology models have inter-business network as its scope. There is no work to capture the ontology of dyadic relationships or external supply chains. Only the EO and TOVE ontologies have formally represented and acknowledged the importance of time. These models could therefore be characterized as dynamic. Other models have adopted a rather static view on a supply chain. The review of supply chain ontology models provides evidence where ontology of a domain is being equated with the knowledge of that domain. The majority of ontological deficiencies inherently present in these models could also be attributed to this. Hence, more rigorous and theoretically sound analysis is required to develop more realistic and robust supply chain systems. By reviewing the supply chain ontology models one gets an impression that problems of supply chain are reduced to identifying the requirements of manufacturing activities. No formal account of other material and information flow supported activities (e.g. replenishment, transport, reverse logistics, etc.) is evident. Broader and more holistic approach is required in order to effectively develop and represent ontology of a supply chain.

According to Greets et. al. [9] technologies like radio frequency identification (RFID) have facilitated the identification of individual things and information sharing regarding their behavior throughout the supply chain. Such developments have generated the capabilities of a supply chain where the location of arbitrary individual things can be determined and monitored at any point in time by all appropriate supply chain partners, made possible by an Internet of Things for the supply chain and ontology facilitates the visibility and interoperability of things along the supply chain. Ontologies like REA (Resource Event Agent) ontology [10] mainly concentrates on business processes like sales, purchases, conversion or manufacturing, human resources and financing. Whereas EAGLET (Event, AGent, Location, Equipment, and Thing) ontology which is newfangled than REA as it also includes the location and equipment, structuring rules, and stereotypical patterns. They are aimed at modeling an item's physical flow through the supply chain, and defining who owns the item and who has custody of it at any point in time. The EAGLET ontology is able to accommodate non manufacturing activities such as replenishment, transportation, and reverse logistics. EAGLET facilitates to model physical flows of things at different levels of granularity tracking and tracing are an integral part of the EAGLET ontology. But it cannot address more supply chain practices, such as the collaboration between supply chain partners to plan and forecast.

Kim, Henry $M$ et al. [11] uses Internet of Things (IoT) and Blockchain technologies which promise to offer provenance even in complex supply chains. Internet- aware sensors capture finely granular real- time data about product and environment characteristics as well as location and time- stamps throughout the supply chain. Furthermore, distributed, shared databases using Blockchain technologies promise to offer highly secure and immutable access to supply chain data. As Blockchain databases are decentralized, so that provenance can be evaluated even when no one party can claim ownership over all supply- chain data.This paper take the TOVE Traceability Ontology [12] as the primary source to design their Blockchain.

According to Pizzuti [13] the ability of monitoring the whole Supply Chain (SC) is obtained assuring the observation of two primary functions: tracking and tracing. The main goal of the proposed FTTO Ontology is to include the most representative food concepts involved in a Supply Chain all together in a single ordered hierarchy, able to integrate and connect the main features of the food traceability domain. The main aim of containing all the information related to the food traceability domain in a unique ontology is directly related with the need of enabling information sharing along the food supply chain. A typical food supply chain is a complex system in which different actors collaborates with each other in order to share information on products and processes. Products include raw ingredients and service products involved in a particular process, such as packaging. Processes are atomic system in different actors execute particular activities that leads to the production of specific food elements. The FTTO ontology devoted to the maintenance of food traceability, capable of enabling interoperability among different systems and integrating the heterogeneous databases adopted by each actor of the food supply chain. In case of food outbreak disease FTTO can be easily queried to obtain essential information fundamental to connect data available in the food supply chain. The ontology querying can be formulated for several purposes, and in particular, for identifying the causes of cases of food outbreak diseases. Pizzuti, Teresa et.al [14] in this paper describes the MEat Supply Chain Ontology (MESCO), an ontology developed for supporting the management of meat traceability along the whole supply chain. In particular, in this paper the authors instantiate MESCO to take the problem of meat traceability from the farmer to the final consumer. The results show that MESCO is able to represent all the knowledge and information related to the meat traceability domain into a single ontology, enabling interoperability among different systems and allowing for integrating the heterogeneous databases adopted by each actor involved in the supply chain. One of the main advantages in using MESCO is the facility in obtaining essential data, fundamental in case of food outbreak disease, addressing the key issues that makes the job of food safety agents frustrating.

According to Yee, Chan Gaik and SMC [15] OSCMS helps to improve the decision making of the manufacturer on supplier selection and at the same time reduce further the operating, distribution and logistics costs, thus saving in time and fuel consumption by avoiding delivery of returnable raw supplies and re-delivery of the qualified supplies.

\section{GAPS IN SUPPLY CHAIN MANAGEMENT}

Food supply chain is a complex system in which different actors collaborates with each other in order to share information on products and processes. For integrating the heterogeneous databases and enabling interoperability between different actors a consistent vocabulary is required for unifying all the information in food supply chain. Acquiring different type of data from various sensors and other resources and integrating it is a huge challenge as data is 
coming in huge volume and also it is not shared between various actors in supply chain. In Indian context of supply chain of perishable food items it is very hard to manage. In India we have unorganized suppliers and producers. There is no implementation of IoT sensors to track the product from most of the suppliers and producers side as people are reluctant to absorb new IoT technologies as they don't have much knowledge about it and also not aware of its cost effectiveness. Also they have small business so they don't have budget to implement IoT. Also it is time consuming process to enter the information of every batch of perishable products like milk, vegetables. As mentioned by report [1] India has the cold storage requirement of 61.13 million metric tons but currently has the capacity for around 32 million metric tons. Cold storage facilities maintain the relative humidity of the agricultural fresh-produce which controls the quality degradation and process contamination. So lack of required cold storage facilities induce huge wastage, also there is shortage of refrigerated carriers for transport which leads to the wastage of food while transporting perishable goods.

Poor logistics infrastructure in India cannot meet the growing demand, and the problems which are pertinent to this sector like lack of skilled labor, higher costs, meager implementation of technology have to be addressed .The design of the logistics network is very crucial for the performance of the supply chains. The proper logistics network design includes decisions like distribution network design which determine the logistics distribution channel, which comprises of warehouses size and the number, crossdocking points and related transportation links. Also fulfilling demand in timely manner, transportation planning which deals with the loading and routing of vehicles to meet customer orders. These issues also not handled by currently available supply chain ontologies.

Integrated IT systems facilitate to achieve high performance supply chains. It helps in standardizing the transaction procedures with the customers and suppliers. These systems provide valuable information for effective decision making. We require ontologies which focus on demand forecast and decision making. Food losses could be largely reduced by an automated demand forecasting system based on better
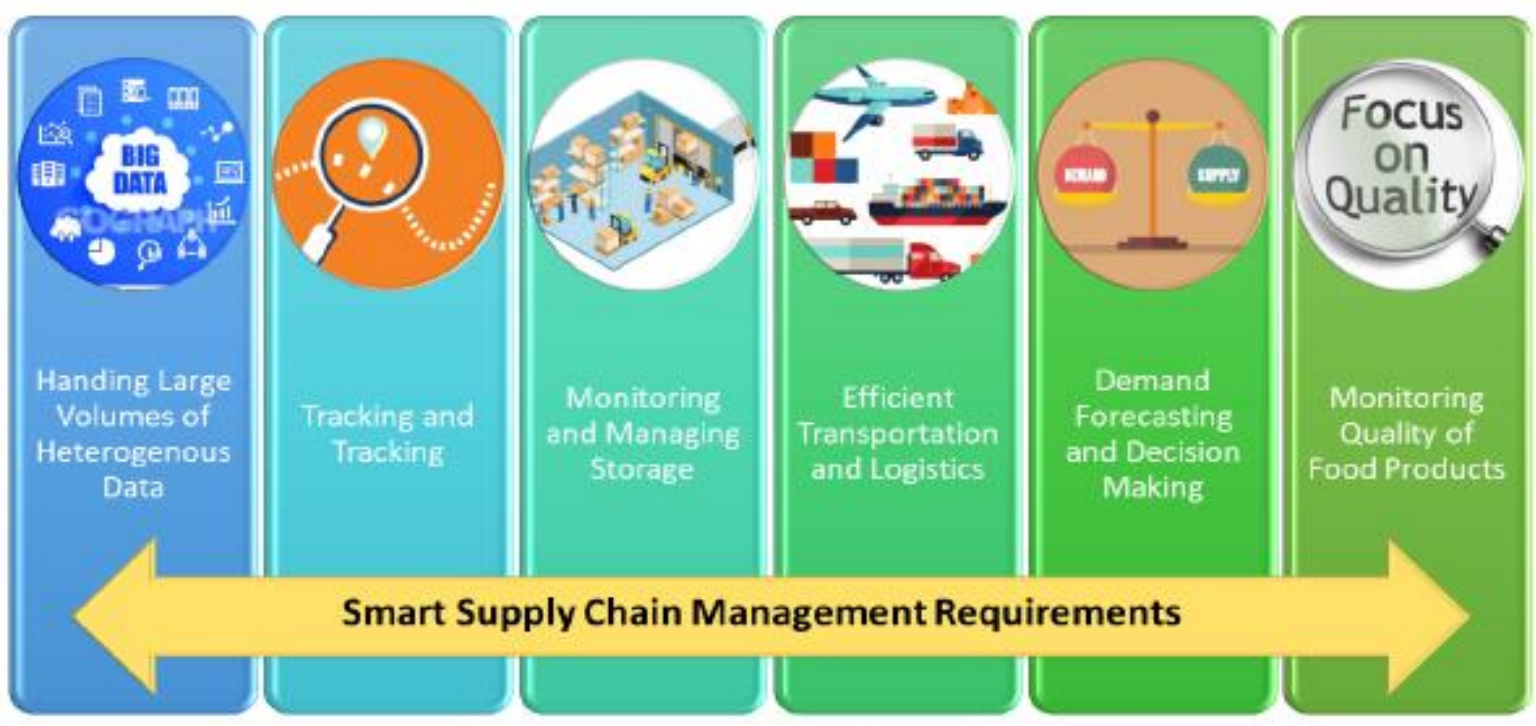

\section{Fig. 2. Food Supply Chain.}




\section{CONCLUSION}

Most of the ontologies for supply chain management for perishable food items focuses only on tracking and traceability but as there are other aspects of supply chain also which needs the attention like forecasting of demand and supply, decision making, efficient transportation system, efficient warehouse management, maintaining and monitoring cold storage facilities for perishable food products. Checking and monitoring quality of food items like milk, vegetables etc. at producer level for adulteration and other chemicals. As per new requirements comes with new technological advancement we need ontologies which can handle all above aspects of food supply chain

\section{REFERENCES}

[1] Vivek Naithani John Bacon, Nitin Khanna. "highvelocity supply chains for perishables: A fresher proposition". Technical report, Cognizant 20-20 Insights, august 2015.

[2] Annibal Scavarda, Gustavo Schiavo, and Andre Korzenowski. The perishable supply chain management: The clients' expectation factors at the chicken supply chain.

[3] Assocham, domestic fruits veggies production to cross 377 million tonne by 2021 : Study, urgent need to enhance production reduce wastage to boost fruits veggie exports, http://assocham.org/newsdetail.php?id=4155, 2013.

[4] Vivek Naithani John Bacon, Nitin Khanna. "indian dairy industry - driven by value-added products". Technical report, Ratings , Indian Dairy Industry - driven by value added products,June 30, 2017.

[5] M Balaji and K Arshinder. Modeling the causes of food wastage in indian perishable food supply chain. Resources, Conservation and Recycling, 114:153-167, 2016.

[6] Vivek Naithani John Bacon, Nitin Khanna. "using ontology to capture supply chain code halos". Technical report, Cognizant keeps challenging, Nov 2014.
[7] S Ureten and H Kemal Ilter. Supply chain management ontology: Towards ontology based scm model. In Proc. of the Fourth Int. Logistics and Supply Chain Management Congress, 2006.

[8] Tonci Grubic and Ip-Shing Fan. Supply chain ontology: Review, analysis and synthesis, Computers in Industry, 61(8):776-786, 2010.

[9] Guido L Geerts and Daniel E O'Leary. A supply chain of things: The eaglet ontology for highly visible supply chains. Decision Support Systems, 63:3-22, 2014.

[10] Frederik Gailly and Geert Poels. Ontology-driven business modeling : improving the conceptual representation of the REA ontology. In International Conference on Conceptual Modeling, pages 407-422. Springer, 2007

[11] Henry M Kim and Marek Laskowski. Toward an ontology-driven blockchain design for supply-chain provenance. Intelligent Systems in Accounting, Finance and Management, 25(1):18-27, 2018.

[12] Michael Gruninger and Mark S Fox. Activity ontology for enterprise modeling. Submitted to AAAI-94, Dept. of Industrial Engineering, University of Toronto, 321, 1994.

[13] Teresa Pizzuti, Giovanni Mirabelli, Miguel Angel SanzBobi, and Fernando Goméz-Gonzaléz. Food track and trace ontology for helping the food traceability control. Journal of Food Engineering, 120:17-30, 2014.

[14] Teresa Pizzuti, Giovanni Mirabelli, Giovanni Grasso, and Giulia Paldino. Mesco (meat supply chain ontology): An ontology for supporting traceability in the meat supply chain. Food Control, 72:123-133, 2017.

[15] Chan Gaik Yee, Arrey Marssaille SMC, and Ida Farisha Moer Alim Shah. An intelligent online supply chain management system for improved decision making on supplier selection. In 2010 Second International Conference on Computer Research and Development, pages 872-875. IEEE, 2010. 